\title{
eEF1By binds the Che-1 and TP53 gene promoters and their transcripts
}

\author{
Cinzia Pisani ${ }^{1 *}$, Annalisa Onori ${ }^{1}$, Francesca Gabanella ${ }^{2,3}$, Francesca Delle Monache ${ }^{1}$, Antonella Borreca ${ }^{2,3}$, \\ Martine Ammassari-Teule ${ }^{2,3}$, Maurizio Fanciulli ${ }^{4}$, Maria Grazia Di Certo ${ }^{2,3}$, Claudio Passananti ${ }^{1}$ and Nicoletta Corbi ${ }^{{ }^{*}}$
}

\begin{abstract}
Background: We have previously shown that the eukaryotic elongation factor subunit 1B gamma (eEF1BY) interacts with the RNA polymerase II (pol II) alpha-like subunit "C" (POLR2C), alone or complexed, in the pol II enzyme. Moreover, we demonstrated that eEF1BY binds the promoter region and the 3' UTR mRNA of the vimentin gene. These events contribute to localize the vimentin transcript and consequentially its translation, promoting a proper mitochondrial network.
\end{abstract}

Methods: With the intent of identifying additional transcripts that complex with the eEF1By protein, we performed a series of ribonucleoprotein immunoprecipitation (RIP) assays using a mitochondria-enriched heavy membrane (HM) fraction.

Results: Among the eEF1By complexed transcripts, we found the mRNA encoding the Che-1/AATF multifunctional protein. As reported by other research groups, we found the tumor suppressor p53 transcript complexed with the eEF1BY protein. Here, we show for the first time that eEF1By binds not only Che-1 and p53 transcripts but also their promoters. Remarkably, we demonstrate that both the Che-1 transcript and its translated product localize also to the mitochondria and that eEF1By depletion strongly perturbs the mitochondrial network and the correct localization of Che-1. In a doxorubicin (Dox)-induced DNA damage assay we show that eEF1By depletion significantly decreases p53 protein accumulation and slightly impacts on Che-1 accumulation. Importantly, Che-1 and p53 proteins are components of the DNA damage response machinery that maintains genome integrity and prevents tumorigenesis.

Conclusions: Our data support the notion that eEF1BY, besides its canonical role in translation, is an RNA-binding protein and a key player in cellular stress responses. We suggest for eEF1BY a role as primordial transcription/translation factor that links fundamental steps from transcription control to local translation.

Keywords: Translation elongation factor, eEF1BY, Che-1, AATF, p53, RIP assay, RNA binding protein, Mitochondria, POLR2C, DNA damage

\section{Background}

The eukaryotic elongation factor 1 subunit gamma $(\mathrm{eEF} 1 \mathrm{~B} \gamma)$, also known as the pancreatic tumor-related protein, is a part of the eEF1 multiprotein macromolecular complex. The eEF1 holoenzyme plays a role in protein synthesis by recruiting the aminoacyl-tRNAs to the A site of the ribosome [1]. Using the current nomenclature for higher eukaryotes, eEF1 consists of two different sub-complexes: eEF1A and eEF1B. eEF1A

\footnotetext{
* Correspondence: cinzia.pisani@uniroma1.it; nicoletta.corbi@uniroma1.it ${ }^{1}$ CNR-Institute of Molecular Biology and Pathology, Department of Molecular Medicine, Sapienza University, Viale Regina Elena 291, 00161 Rome, Italy Full list of author information is available at the end of the article
}

(formerly eEF1 $\alpha$ ) is a single polypeptide, whereas eEF1B is a multimer of eEF1B $\alpha$ (formerly eEF1 $\beta$ ), eEF1B (formerly

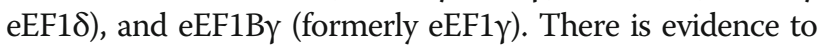
indicate that eEF1By stimulates, but is not required for, the catalytic activity of eEF1B $\alpha[2,3]$. Indeed, eEF1By appears dispensable for translation, and its absence does not seem to affect the global rate of translational elongation $[4,5]$. Nevertheless, multiple non-canonical roles for eEF1By are emerging, some of which can be regulated by phosphorylation driven by several protein kinases [6]. A role of eEFB1 $\gamma$ in the oxidative stress response pathways is justified by the presence in the $\mathrm{N}$ terminus of a conserved sequence resembling the glutathione-binding region of the theta class of 
glutathione S-transferase (GST) enzymes, which are involved in the detoxification of oxygen radicals. The overexpression of the eEF1By gene product has been reported in several tumors, including pancreatic, breast, colon, and gastric tumors [7-11]. There is growing evidence that the elongation step is also regulated in response to environmental cues, supporting the idea that deregulation of translational control serves as a common mechanism by which diverse oncogenic pathways promote cellular transformation and tumor development $[12,13]$. In a wider context, aberrant proliferation of cancer cells is supported by adaptation to nutrient microenvironment mediated by a dynamic metabolic reprogramming [14]. Importantly, the level of eEF1BY upregulation was shown to positively correlate with tumor aggressiveness, presumably due to an altered redox balance $[2,15,16]$. eEF1By displays an affinity for membrane and cytoskeleton elements, and it can properly anchor the different subunits of the EF1 complex to the cytoskeleton $[2,6,17]$. Interestingly, Al-Maghrebi et al. (2002) demonstrated the RNA-binding properties of $\mathrm{eEF} 1 \mathrm{~B} \gamma$ by showing for the first time its binding to the 3' UTR of vimentin mRNA [18], suggesting that eEF1By could exert many of its biological functions through the binding of a pool of mRNAs. In addition, human $\mathrm{eEF} 1 \mathrm{~B} \gamma$ was recently identified in a proteomic screen as a member of the pre-mRNA 3' end cleavage complex [19]. In this context, eEF1By could participate in the anchoring and translation of a set of mRNAs that are preferentially translated on cytoskeletal- or membrane-bound ribosomes, such as vimentin mRNA. Vimentin has been recently reported to have a regulatory role in supporting the morphology, organization and function of mitochondria $[20,21]$. Importantly we previously demonstrated that eEF1By partially co-localizes with mitochondria [5]. Yoo's research group showed that $\mathrm{hCdc} 73$, a component of the human RNA polymerase II-associated factor complex (PAFc), binds and destabilizes p53 mRNA via eEF1By, thus acting as a binding platform [22]. They proposed that misregulation of this interaction may lead to tumor progression. Liu et al. reported a new role for eEF1By in the activation of the NF-Kb signaling pathway, through targeting the mitochondrial antiviral adaptor protein (MAVS), which bridges viral RNA recognition and downstream signal activation [23]. The Esposito research group showed that the TNF receptor associated protein (TRAP1), a mitochondrial member of the HSP90 family, which is involved in the protection of oxidative stress, selectively binds eEF1By, and, remarkably, both TRAP1 and eEF1By are coupregulated in human colorectal cancers [24]. We have previously shown that $\mathrm{eEF} 1 \mathrm{~B} \gamma$ interacts with the RNA polymerase II (pol II) alpha-like subunit "C" (POLR2C), alone or complexed, in pol II [25-27]. The POLR2C/POLR2J heterodimer (also called RPB3/RPB11) is reminiscent of the $\alpha$ subunit homodimer of bacterial RNA polymerase [28]. In bacteria, the alpha subunit homodimer associates with $\sigma$ factors that mediate promoter recognition [29-31]. Moreover, eEF1By has been described to bind the vimentin 3' UTR, and we have shown that it also binds the promoter region of the vimentin gene $[5,18]$. These results suggest that eEF1By has a role in shuttling/nursing vimentin mRNA (and presumably a specific set of mRNAs) from their gene locus to their appropriate cellular compartment for translation. On the basis of eEF1By sub-cellular localization and its involvement in RNA metabolism and mitochondria/cytoskeleton organization, herein, using a mitochondria-enriched heavy membrane (HM) fraction, we identified, by ribonucleoprotein complex immunoprecipitation (RIP assay), several novel transcripts that complexed with eEF1By. Among the isolated mRNAs, we found genes involved in translation and in mitochondrial/cytoskeleton metabolism. In particular, we found the mRNA of the pol II binding protein Che-1/AATF, and we confirmed the presence of the p53 transcript [22]. Che-1 plays a role in multiple fundamental processes, including control of transcription, cell cycle regulation, DNA damage responses and apoptosis [32-34]. Recent studies suggest that Che-1 protein level dysregulation could be relevant for the transformation process. Che- 1 is found upregulated in several leukemia cell lines and in patient with chronic lymphocytic leukemia [33].

Loss or mutation of the oncosuppressor p53 is strongly associated with the susceptibility to cancer and to malignant tumor progression [35, 36]. Notably, Che-1 directly binds p53 and is an important regulator of p53 activity [37]. Moreover, Che-1 enhances the oncogenic potential of the mutated forms of the oncosuppressor p53 (mtp53) [34, 38].

Here, we show for the first time that eEF1By binds to the Che- 1 and TP53 promoter regions. In addition, we describe a novel mitochondrial localization for the Che1 protein, and we show that Che- 1 needs mitochondrial integrity for correct localization. We suggest a role for eEF1By as a primordial transcription/translation factor that links the fundamental steps between transcription control and local translation.

\section{Methods}

\section{Constructs}

The myc-tagged pCS2-eEF1BY (Myc-eEF1By) (UniProtKB: P26641) construct and its derived deletion mutants were generated by PCR amplification or sub-cloning [5].

The MS2 system vectors were generously provided by Dr. Robert Singer (Albert Einstein College of Medicine, NY). The reporter transcript constructs (Report mRNAs) were obtained by subcloning, in the pMIR-REPORT ${ }^{\mathrm{m}}{ }^{-}$ Luciferase plasmid, the 12 repetitions of MS2 RNA stem loop, amplified from pSL1180 vector, and the selected 3' UTR, amplified from a cDNA library, using the appropriate primers (Additional file 1, Table S1). All constructs were DNA-sequenced by Eurofins Genomics. 


\section{Cell culture and transfections}

HeLa human cervical cancer cells and HCT116 human colon carcinoma cells were grown in Dulbecco's modified Eagle's medium (DMEM) supplemented with $10 \%$ foetal bovine serum (Gibco-BRL, Grand Island, NY, USA). hSHSY5Y neuroblastoma cells were grown in DMEM supplemented with $15 \%$ foetal bovine serum. All cell cultures were maintained at $37^{\circ} \mathrm{C}$ in a humidified atmosphere of $5 \% \mathrm{CO}_{2}$. Transient transfections were performed using Lipofectamine or Lipofectamine 2000 reagents (Thermo Fisher Scientific, Inc., Waltham, MA, USA), according to the manufacturer's instructions.

The siRNA-mediated interference experiments for eEF1By expression were performed by transfecting SMART poolspecific or non-specific control pool double-stranded RNA oligonucleotides (GE Healthcare Dharmacon Inc., Lafayette, CO, USA) using Lipofectamine 2000.

Drug treatment with doxorubicin $(1 \mu \mathrm{M})$ (SigmaAldrich Co., St. Louis, MO, USA) was carried out by incubating cells with the indicate concentration of the drug in fresh media for either $1 \mathrm{~h}$ or $2 \mathrm{~h}$ before analysis.

\section{Sub-cellular fractionation}

The mitochondria-enriched heavy membrane (HM) fraction were obtained as previously described [39]. Briefly, HeLa cells $\left(\sim 6 \times 10^{6}\right)$ were harvested in lysis buffer (250 mM sucrose, $20 \mathrm{mM}$ Hepes, pH 7.5, $10 \mathrm{mM} \mathrm{KCl}$, $1.5 \mathrm{mM} \mathrm{MgCl}_{2}, 1 \mathrm{mM}$ EDTA, $1 \mathrm{mM}$ EGTA) and complete protease inhibitor (Roche, Indianapolis, IN, USA). The cells were disrupted by twelve passages through a 25 -gauge needle. The HM fractions were obtained by centrifugation at $10,000 \mathrm{~g}$ for $10 \mathrm{~min}$. The HM pellet was resuspended in high stringency buffer $(50 \mathrm{mM}$ Tris- $\mathrm{HCl} \mathrm{pH} 7.4,250 \mathrm{mM}$ $\mathrm{NaCl}, 5 \mathrm{mM}$ EDTA, 10 \% glycerol, $0.5 \%$ Igepal-CA 630) plus a proteinase inhibitor cocktail (Complete ${ }^{\mathrm{Tw}}$, Roche, Indianapolis, IN, USA).

The mitochondrial fraction was purified from HeLa and hSH-SY5Y cells $\left(\sim 2 \times 10^{7}\right)$ using a Qproteome Mitochondria Isolation Kit (Qiagen, Hilden, Germany) as previously described [5].

\section{Immunoblotting}

Whole-cell lysate was obtained as previously described, and sub-cellular fractionations (see above) were analyzed by western blotting [5]. The publicly available software ImageJ (National Institutes of Health, USA) was used to quantify the densitometry of the immunoblot bands.

\section{RIP assay}

Mitochondria-enriched heavy membrane (HM) fraction or whole-cell extracts were prepared as above in the presence of RNase inhibitors (Thermo Fisher Scientific, Inc., Waltham, MA, USA). For the immunoprecipitation assay, the protein lysate was pre-cleared for $1 \mathrm{~h}$ at $4{ }^{\circ} \mathrm{C}$ with Protein A/G-Agarose beads (Roche, Indianapolis, IN, USA) and then immunoprecipitated overnight with the anti-eEF1By rabbit polyclonal antibody or with antimyc monoclonal antibody. A "no-antibody" immunoprecipitation was performed as a negative control. The beads were washed five times for $5 \mathrm{~min}$ at $4{ }^{\circ} \mathrm{C}$ with a high stringency buffer and once in PBS buffer. The beads containing the immunoprecipitate samples were collected and resuspended in buffer $\mathrm{R}$ (50 mM Tris- $\mathrm{HCl} \mathrm{pH} \mathrm{7,} 10 \mathrm{mM}$ DTT, 5 mM EDTA, $1 \%$ SDS) [40]. A portion of immunoprecipitation was processed for western blot analysis. RNA was extracted using TRIzol ${ }^{\circ}$ reagent (Thermo Fisher Scientific, Inc., Waltham, MA, USA) according to the manufacturer's instructions. RNAs were converted to cDNAs and randomly amplified using a Full Spectrum ${ }^{\text {tw }}$ Complete Transcriptome RNA Amplification Kit (System Biosciences, Mountain View, CA, USA) according to the manufacturer's protocol. cDNA was run on a $2 \%$ agarose gel, and the portion between 200 and $500 \mathrm{bp}$ was isolated and cloned into pGEM-T vectors using a pGEM ${ }^{\bullet}$-T Easy Vector System (Promega, Madison, WI, USA) according to the manufacturer's instructions. The obtained clones were analyzed by EcoRI digestion, and the selected clones were sequenced by Eurofins MWG Services.

\section{RNA extraction, retrotranscription and quantitative real- time PCR (qPCR)}

Total RNA from HeLa and hSH-SY5Y cells was extracted using TRIzol ${ }^{\circ}$ reagent according to the manufacturer's instructions and was then reverse transcribed using a High Capacity cDNA Reverse Transcription kit (Thermo Fisher Scientific, Inc., Waltham, MA, USA). A quantitative realtime PCR ( $\mathrm{qPCR}$ ) assay was performed in triplicate in a 96-well format in an ABI Prism 7000 Sequence Detection System (Applied Biosystems, Foster City, CA, USA) using the SYBR Green PCR Master mix. GAPDH or MT-ND2 was used for the normalization of mRNA, and the relative expression was calculated using the comparative $\mathrm{Ct}$ method $\left(2^{-\Delta \Delta C t}\right)$. Primer sequences used in this study are shown in Additional file 1: Table S1.

\section{Chromatin immunoprecipitation (ChIP) assay}

A chromatin immunoprecipitation assay was performed as previously described [41]. Equal amounts of chromatin from each sample were immunoprecipitated overnight with anti-eEF1By rabbit polyclonal antibodies. The immunoprecipitated sonicated chromatin was amplified using human Che-1-specific primers, human thymidine kinase (TK)-specific primers and human $\mathrm{p} 53$-specific primers. The PCR conditions were as follows: 30 cycles at $95{ }^{\circ} \mathrm{C}$ for $45 \mathrm{~s}, 60$ $67{ }^{\circ} \mathrm{C}$ for $30 \mathrm{~s}, 72{ }^{\circ} \mathrm{C}$ for $30 \mathrm{~s}$ and a final extension at $72{ }^{\circ} \mathrm{C}$ for $5 \mathrm{~min}$. 


\section{Polysome profile analysis}

The polysomal profile analysis was performed as previously described [42]. Briefly, cells were homogenized in lysis buffer $(10 \mathrm{mM}$ Tris- $\mathrm{HCl} \mathrm{pH} \mathrm{7.5,} 100 \mathrm{mM} \mathrm{NaCl}$, $10 \mathrm{mM} \mathrm{MgCl} 2,1$ \% Triton X-100, $30 \mathrm{U} / \mathrm{ml}$ RNasin). Lysates were incubated on ice for $5 \mathrm{~min}$ and then centrifuged at $12,000 \mathrm{rpm}$ for $5 \mathrm{~min}$ at $4{ }^{\circ} \mathrm{C}$. Supernatants were immediately loaded onto a $10 \mathrm{ml} 15-50 \%(\mathrm{w} / \mathrm{v})$ sucrose gradient and centrifuged at $37,000 \mathrm{rpm}$ for 180 min at $4{ }^{\circ} \mathrm{C}$ at in a Beckman SW41 rotor. For EDTA treatments, $100 \mathrm{mM}$ EDTA was added to the cytoplasmic extracts before stratification on a sucrose gradient. Free ribosomal subunits (60S and 40S), monosomes (80S), large polysomes, and the very light mRNPs were detected by UV absorbance at $254 \mathrm{~nm}$ using a BioLogic LP system (BioRad Inc., Hercules, CA, USA). Each gradient was collected in 9 fractions, and the proteins were precipitated with a mix containing $50 \%$ ethanol, $25 \%$ methanol and $25 \%$ acetone and were then processed for western blot analysis.

\section{Immunofluorescence and confocal laser scanning microscopy}

Cells were fixed with $4 \%$ formaldehyde in PBS, permeabilized in 0.2 \% Igepal-CA 630 (Sigma Chemical Co., St. Louis, MO, USA) for $10 \mathrm{~min}$, and blocked with $1 \%$ BSA in PBS at room temperature. Samples were incubated sequentially with the appropriate primary and secondary antibodies. Slides were mounted with ProLong with DAPI (Thermo Fisher Scientific, Inc., Waltham, MA, USA) or Hoechst 33258 solution (Sigma Chemical Co., St. Louis, MO, USA). To label mitochondria, cells were incubated with $250 \mathrm{nM}$ of MitoTracker ${ }^{\circledR}$ Red CMXRos M7512 (Thermo Fisher Scientific, Inc., Waltham, MA, USA) according to the manufacturer's instructions and then were fixed and incubated with anti-Che-1 rat polyclonal antibodies. Slides were examined by conventional epifluorescence microscopy (Olympus BX51). Images were captured using a digital camera SPOT RT3 and merged using the IAS2000 software. For confocal laser scanning microscopy, slides were examined with a confocal system TCS-SP5 (Leica Microsystem, GmbH Wetzlar, Germany).

\section{RNA-FISH combined with immunofluorescence}

HeLa cells were processed for immunofluorescence in the presence of RNase inhibitors, with secondary antibody incubation subsequent to FISH to prevent denaturation of the antibodies. FISH was performed using a FITC labeled oligonucleotide probe (Additional file 1: Table S1) [43, 44]. The cells were fixed in $4 \%$ paraformaldehyde in PBS (pH 7.4) for $30 \mathrm{~min}$ and washed three times with PBS and $0.2 \%$ Igepal-CA 630 for $5 \mathrm{~min}$. The slides were then permeabilized by treatment with $70 \%$ ethanol overnight at $4{ }^{\circ} \mathrm{C}$. The cells were rehydrated for $5 \mathrm{~min}$ in $50 \%$ formamide, $2 \times \mathrm{SCC}(300 \mathrm{mM} \mathrm{NaCl}$, $30 \mathrm{mM}$ sodium citrate, $\mathrm{pH}$ 7.0) and pre-hybridized with hybridization buffer (50\% formamide, $10 \%$ dextran sulfate, $2 \mathrm{mM}$ vanadyl-ribonucleoside complex, $40 \mu \mathrm{g} E$. coli tRNA, $2 \times$ SSC) for $1 \mathrm{~h}$ at $37^{\circ} \mathrm{C}$. Then, cells were incubated overnight with 30 ng FITC labeled DNA oligonucleotide probe in $40 \mu \mathrm{l}$ hybridization buffer at $37^{\circ} \mathrm{C}$. The coverslips were washed twice in $2 \times \mathrm{SCC} / 50 \%$ formamide at $37{ }^{\circ} \mathrm{C}$ and twice in $1 \times$ SCC at room temperature. The coverslips were incubated with anti-FITC primary antibodies (to amplify the signal) and the appropriate secondary antibodies in $1 \%$ blocking reagent solution (Roche, Indianapolis, IN, USA) at room temperature and mounted with ProLong with DAPI. The slides were examined by conventional epifluorescence microscopy (Olympus BX51). The images were captured using a digital camera SPOT RT3 and merged using IAS2000 software. Co-localization analysis was performed using Image J software (Image J, Colocalization Coloc 2, Intensity correlation quotient (ICQ)). The ICQ value is calculated based on Li's intensity correlation analysis, which is considered a stable method for colocalization analysis as it allows the discrimination of coincidental events in a heterogeneous situation. ICQ varies from -0.5 (exclusion) to 0.5 (complete co-localization) [45]. Region-of-Interest (ROI) were drawn around single cells. Background and threshold correction were applied for each ROI.

\section{Antibodies}

The following antibodies were used: anti-eEF1By rabbit polyclonal antibody (Bethyl Laboratories, Inc. Montgomery, TX, USA), for western blotting and immunoprecipitation; anti-eEF1By mouse monoclonal antibody (Abnova, Taipei City, Taiwan), for immunofluorescence; anti-myc monoclonal antibody (9E10 clone, hybridoma-conditioned medium), for western blotting and immunoprecipitation; anti-Tom20 rabbit polyclonal antibody (Santa Cruz Biotechnology, Santa Cruz, CA, USA), for western blotting and immunofluorescence; anti-SMN mouse monoclonal antibody (BD Transduction Laboratories, San Jose, CA, USA), for western blotting; anti-L7 rabbit monoclonal antibody (Abcam, Cambridge, UK), for western blotting; anti-S6 rabbit polyclonal antibody (Cell Signaling Technology, Danvers, MA, USA), for western blotting; anti- $\gamma$-tubulin monoclonal antibody (Merck Biosciences, Kenilworth, NJ, USA), for western blotting; anti-Che-1 rabbit polyclonal antibody [46], for western blotting; antiHSP60 monoclonal antibody (Santa Cruz Biotechnology, Santa Cruz, CA, USA), for western blotting; anti $\beta$-actin (Sigma-Aldrich Co., St. Louis, MO, USA), for western blotting; anti-FITC mouse monoclonal antibody (Sigma Chemical Co., St. Louis, MO, USA), for RNA-FISH. For Che-1 rat antiserum production, Wistar rats were immunized four 
times with $250 \mu \mathrm{g}$ of the purified His tag Che-1 protein every week using Freund's adjuvants (Difco, Detroit, MI, USA); antiserum was collected 5 days after the last injection. All procedures were carried out in accordance with the ethical guidelines for animal care of the European Community Council (directive 2010/63EU). Housing of the animals meets the behavioral needing of the specie and was supervised by the Responsible Veterinarian. The secondary antibodies conjugated to horseradish peroxidase were purchased from GE Healthcare (GE Healthcare, Chicago, IL, USA). Alexa-Fluor-488 or Alexa-Fluor-594-conjugated secondary antibodies were purchased from Thermo Fisher Scientific (Thermo Fisher Scientific, Inc., Waltham, MA, USA).

\section{Results}

\section{eEF1By binds specific mRNAs and their gene promoter} regions

The eEF1By protein has been shown to associate with both the vimentin promoter and vimentin 3' UTR mRNA, thus influencing the cellular shape and mitochondria localization $[5,18]$. Here, with the intent of identifying additional transcripts complexed with the eEF1By protein, we performed a series of ribonucleoprotein immunoprecipitation (RIP) assays. A scheme of the RIP assay protocol is shown in Fig. 1a. The HeLa cell mitochondria-enriched HM fraction was immunoprecipitated with anti-eEF1B $\gamma$ polyclonal antibodies (Fig. 1b). The co-immunoprecipitated RNA was purified and retro-transcribed. The cDNA output was randomly amplified, size selected and cloned. Fig. 1c shows the resulting HM-cDNA library. Interestingly, among the mRNAs complexed with eEF1By, we isolated the Che-1/AATF mRNA. The RT-PCR analysis, shown in Fig. 1d, demonstrated the presence of Che-1 mRNA in eEF1By RIP assay output.

Although in a specific subcellular fraction, we confirmed the presence of vimentin and p53 transcripts, as previously reported $[18,22]$. Additional file 2 : Table S2 shows a list of selected individual clones randomly sequenced from

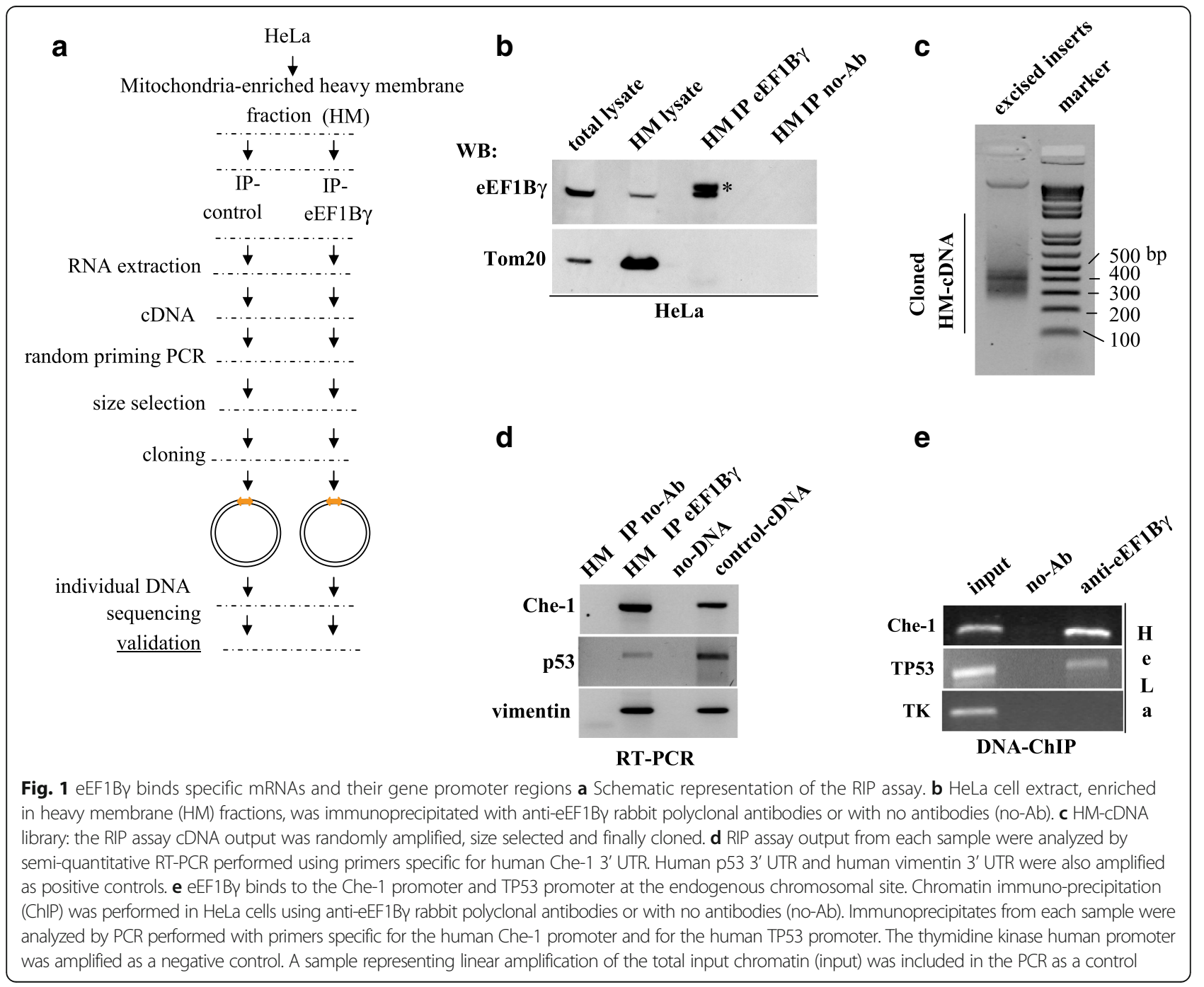


the mitochondria-enriched heavy membrane (HM)-cDNA library. Additional file 3: Figure S1A shows the RT-PCR validation of some of the individual clones. The finding of the Che-1 transcript in the eEF1By RIP assay output is consistent with the presence of eEF1By on the Che-1 promoter that we have communicated in our previous manuscript [5]. As shown in Fig. 1e, by DNA ChIP analysis in Hela cells, we confirmed the presence of eEF1By on the Che-1 promoter, and, importantly, we showed for the first time the presence of eEF1By on the TP53 gene promoter. The ChIP experiments were also performed on human neuroblastoma hSH-SY5Y cells, confirming the data (Additional file 4: Figure S2A).

\section{eEF1By co-localizes with specific mRNAs}

It has been shown that in vimentin 3' UTR mRNA, eEF1By binds an RNA element named the "Y shaped structure", which exhibits striking sequence homology across species [47, 48]. Moreover, Sasvari et al. demonstrated a role for eEF1By in Tomato bushy stunt virus (TBSV) replication by interacting with a stem-loop structure at the 3' end of the viral RNA [49]. Interestingly, as shown in Fig. 2a, the human Che-1 3' UTR mRNA is characterized by a stem-loop secondary structure folded according to the dynamic programming algorithm originally proposed by Zuker and Stiegler [50]. To visualize and validate the interaction between eEF1By and the Che-1 3 'UTR, we performed an MS2 assay [51]. Figure 2b (left panel) shows a schematic representation of the MS2 assay. Briefly, the MS2-GFP system is based on two components: a fusion of the MS2 coat protein with the GFP protein carrying a nuclear localization signal NLS (MS2-GFP) and a reporter transcript (Report mRNA) containing multimers of the RNA stem-loop, recognized by the MS2-GFP protein, upstream of the 3' UTR of the mRNA of interest. MS2-GFP chimeric protein, over-expressed alone in mammalian cells, shows a nuclear localization, whereas when it binds to the RNA stem-loop, it tends to move in the cytoplasmic compartment. As shown in Fig. 2b (right panel), MS2-GFP protein expressed in HeLa cells alone or with the 3' UTR of Che-1 or vimentin was analyzed in the presence or
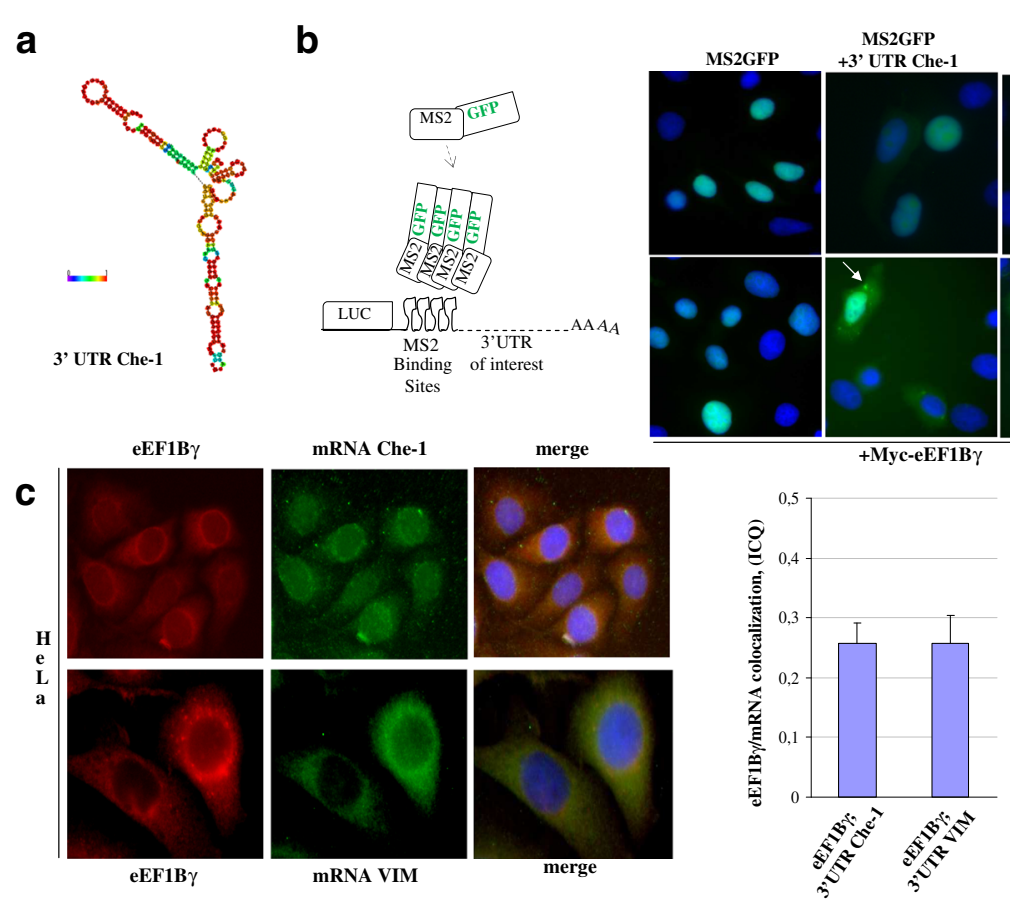

Fig. 2 eEF1By co-localizes with specific mRNAs a The human Che-1 3' UTR was folded according to the computer algorithm of Zuker and Stiegler to yield a structure of minimum free energy [65]. $\mathbf{b}$ Schematic representation of the chimeric bacteriophage MS2 coat protein fused to the GFP protein (MS2-GFP) and the reporter transcript containing multimers of the RNA stem-loop, recognized by the MS2-GFP protein, upstream of the 3' UTR of the mRNA of interest named: "Report mRNA" (left panel). The MS2-GFP protein was expressed in HeLa cells either alone or with the Report mRNA carrying the 3' UTR of Che-1 or vimentin mRNAs (upper panel). In the lower panel, MS2-GFP was co-expressed with myc-eEF1By protein and with the Report mRNA carrying either the 3' UTR of Che-1 or the 3'UTR of vimentin transcripts (right panel). c Co-localization of endogenous eEF1BY protein and either Che-1 or vimentin endogenous mRNAs in HeLa cells. Expression of eEF1By was detected by indirect immunofluorescence using polyclonal eEF1By antibodies (red), whereas Che-1 and vimentin mRNAs (green) were detected by RNA-FISH. Nuclei (blue) were stained with DAPI. Intensity correlation quotient (ICQ) shown in the bar graph was calculated using Coloc 2 plugin in the Image J/Fiji software and indicates whether the intensity of co-staining varies in synchrony over space. The values indicated represent an average over at least 10 cells from different images and the error bars indicate standard error 
absence of myc-eEF1By. Only in the presence of myceEF1By a clear dot fluorescent pattern is observed in the cytoplasmic compartment. Additional file 3: Figure S1B shows additional MS2 assays performed on different mRNAs complexed with eEF1By (see Additional file 2: Table S2). As shown in Fig. 2c, to visualize co-localization of endogenous eEF1By protein and endogenous Che- 1 or vimentin mRNAs, we performed RNA-FISH analysis combined with indirect eEF1By-immunofluorescence in HeLa cells. We quantified eEF1By/3'UTR mRNA co-localization by measuring intensity correlation quotient (ICQ) values as shown in the bar graph.

\section{Characterization of the eEF1B $y$ mRNA binding property}

Taking into account that eEF1By acts as an RNAbinding protein, we assessed the eEF1By distribution in a polysomal profile in HeLa cells (Fig. 3a, right). Cytoplasmic extracts were subjected to ultracentrifugation in a sucrose density gradient in the presence or absence of EDTA. The EDTA treatment dissociated the large and small ribosomal subunits and virtually disrupted all polyribosomes. In our experimental conditions, eEF1By protein was mainly retained in slow-sedimenting fractions that were enriched in ribonucleoprotein particles (mRNPs) (Fig. 3a, left). We also tested the distribution

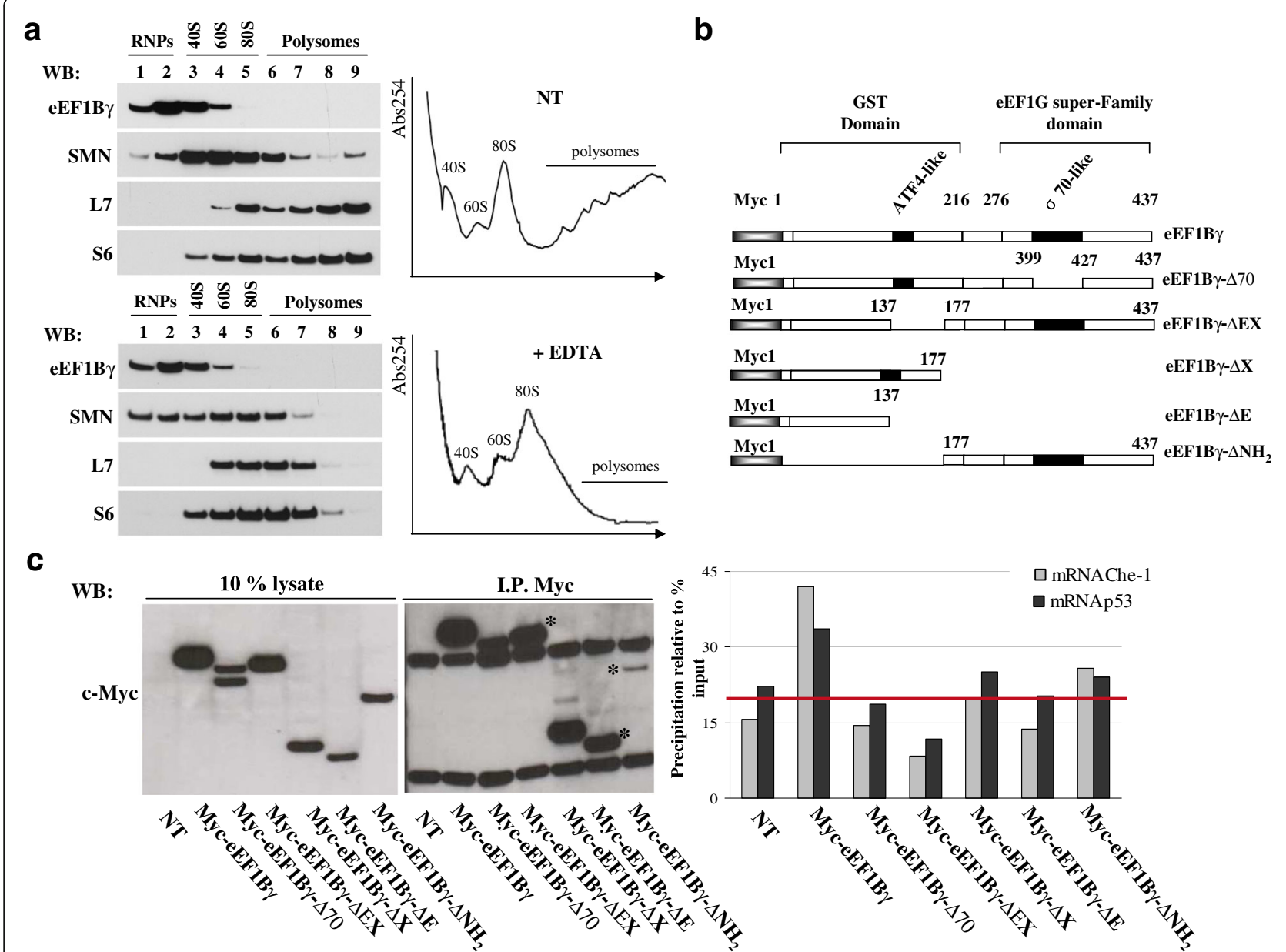

Fig. 3 Characterization of the eEF1BY mRNA binding property a Polysome profiles of HeLa cells by sedimentation velocity through sucrose density gradients. Cytoplasmic extracts were untreated (NT) or treated with 100 mM EDTA to dissociate polyribosomes. Representative absorbance profiles at $254 \mathrm{~nm}$. The 805 monosome peak is indicated (right). Western blot analysis showing the distribution of the eEF1By protein in fractions collected from the top to the bottom of the sucrose gradient. Samples corresponding to mRNPs, 40S, 60S, 80S monosomes and polysomes fractions are indicated. SMN and the ribosomal proteins S6 and L7 were used as controls (left). b Schematic representations of myc-tagged full-length eEF1BY and its derived deletion mutants transiently transfected in HeLa cells analyzed in panel c. c RIP assays were performed with an anti-myc tag antibody. Immunoprecipitated samples were analyzed by western blotting using the myc-tag monoclonal antibodies to verify IP efficiency. The asterisks mark the signal corresponding to the eEF1By mutant, partially covered by the heavy chain lg band (top) and a non-specific band (bottom). The total cell lysates were immunoblotted to verify the correct expression of the transfected molecules (left). On the right, the graph shows the analysis of mRNAs immunoprecipitated with the indicated constructs. The data are expressed as percent precipitation relative to input mRNAs. The horizontal line illustrates the mean background level 
of the survival motor neuron (SMN) protein because it has been demonstrated that this RNA-related protein associates with polyribosomes $[42,52]$. The protein composition of each collected fraction was validated using S6 and L7 antibodies to monitor the small and large ribosomal subunits, respectively. The eEF1By protein is a multi-domain polypeptide that harbors a GST like domain on the N-terminus and an eEF1G super-family domain at the carboxyl terminus (ref: pFAM 00147). In addition, in the carboxyl terminus, there is a region with $74 \%$ homology to the sigma-70 factors ECF subfamily signature (ref: PDOC00814). To identify the eEF1By domain/s responsible for Che-1 and p53 mRNA interactions, a series of eEF1By deletion mutants fused to the myc tag was constructed (Fig. 3b). HeLa cells were transiently transfected with myc-eEF1By or with its deletion mutants to perform a RIP assay analysis. The immunoprecipitations, performed using myc-tag antibodies, were analyzed by western blotting as shown in Fig. 3c (left panel), and co-immunoprecipitated mRNAs were extracted and converted to cDNA. Che- 1 and p53 mRNAs co-immunoprecipitated with the indicated constructs were plotted in a graph. The data are expressed as percent precipitation relative to the input mRNAs. The mean background level is illustrated by the horizontal line in the graph [53]. By RT-PCR, the cDNA output confirmed the presence of both Che-1 and p53 transcripts in full-length eEF1B $\gamma$ and their limited presence in deletion mutants eEF1B $-\Delta \mathrm{NH}_{2}$ and eEF1B $\gamma-\Delta \mathrm{X}$.

\section{Che-1 protein mitochondria localization and eEF1By depletion effects}

We previously demonstrated that eEF1By contributes to govern the correct localization of vimentin intermediatefilament protein, which is known to be involved in cell morphology and organelle positioning [5]. Because the Che-1 protein was observed in both the nucleus and cytoplasmic organelles [33, 54, 55], we examined Che-1 sub cellular localization in more detail. In Fig. 4a (left panel), using the rat Che-1 antibody in a dual-label immunofluorescence assay with mitochondrion-selective dye MitoTracker (red), we detected novel localization of Che-1 protein in mitochondria. To further verify the Che-1 mitochondrial localization, we used the mitochondrial marker Tom20 in a dual-label immunofluorescence assay in hSH-SY5Y cells. Extensive co-localization between endogenous Che- 1 and Tom 20 is revealed by the merged-color image (Additional file 4: Figure S2B). Western blot analysis of the mitochondria-enriched heavy membrane (HM) fraction, prepared from HeLa cells, clearly confirmed a Che-1 mitochondrial association (Fig. 4a, right panel). Che-1 mitochondrial localization was also observed in the mitochondrial fraction prepared from hSH-SY5Y cells (Additional file 4: Figure S2C). To investigate the possible effects of eEF1By depletion on mitochondrial Che-1 expression levels, quantitative real time PCR (qPCR) and western blot analyses were performed with HeLa cells. In our experimental conditions, eEF1B $\gamma$ knockdown did not produce any significant change in Che-1 expression levels (both RNA and protein levels) in mitochondriaenriched HM fractions (Fig. 4b, c). The same results were obtained using a purified mitochondrial fraction (Fig. 4b, c). We also checked transcript and protein levels of Che-1 upon eEF1B $\gamma$ depletion by analyzing the whole-cell lysate. Histograms presented in Additional file 3: Figure S1C and S1D show almost no changes in Che-1 levels. Similar results were obtained when $\mathrm{qPCR}$ was performed on representative mRNAs co-immunoprecipitated with eEF1By (Additional file 2: Table S2 and Additional file 3: Figure S1C). Equivalent results were obtained for eEF1By siRNA in the hSH-SY5Y cell line (Additional file 4: Figure S2D and E). Next, we investigated the mitochondrial localization of Che-1 by indirect immunofluorescence with both antiTom 20 antibodies and rat anti-Che- 1 antibodies in HeLa cells treated with eEF1By siRNA. Figure $4 d$ shows the results of mitochondrial fragmentation, swelling and disorganization. The mitochondrial network was severely compromised (fragmented) and the co-localization Che-1/ Tom 20 was partially lost.

\section{eEF1B $y$ in cellular responses to genotoxic stress}

Because our data on eEF1B $y$ depletion indicated almost no changes in the Che-1 and p53 levels, we investigated the possible impact of eEF1By in stress pathways shared by Che- 1 and $\mathrm{p} 53$, such as genotoxic stress induced by treatment with doxorubicin (Dox). To this end, we examined the effect of eEF1By depletion on Che-1 and p53 mRNA and protein levels in HCT116 cells during Doxinduced DNA damage. As shown in Fig. 5a, quantitative real time PCR (qPCR) analysis indicated that HCT116 cells transiently transfected with either siRNA-eEF1By or siRNA-Control and treated with $1 \mu \mathrm{M}$ Dox at one hour and two hours did not display significant changes of both p53 and Che- 1 mRNA levels. Only a slightly decrease of Che- 1 and p53 transcripts was detected when Dox treatment was coupled with eEF1By depletion. Western blot analysis indicated that HCT116 cells transiently transfected with either siRNA-eEF1By or siRNAControl and treated with $1 \mu \mathrm{M}$ Dox at one hour and two hours produced an evident decrease of p53 protein accumulation and a slight decrease of Che-1 protein accumulation (Fig. 5b) [33, 56].

\section{Discussion}

It is clear that eEF1B $\gamma$, in addition to its canonical role in the translation elongation complex, displays RNA binding ability [18, 22, 48]. In particular, eEF1By has been shown to bind the vimentin 3' UTR, and we have 


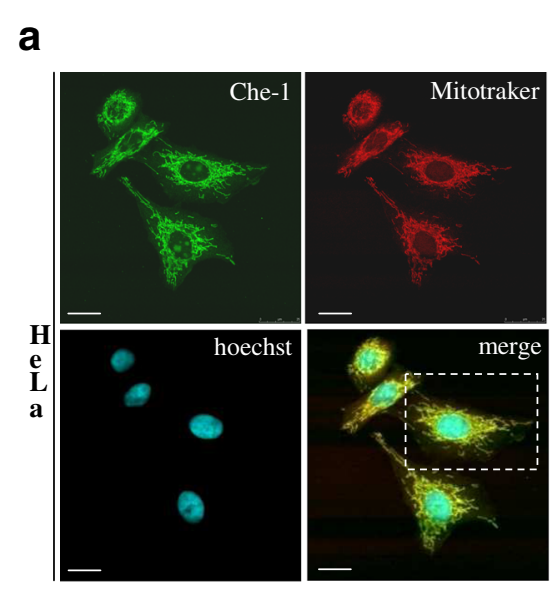

C

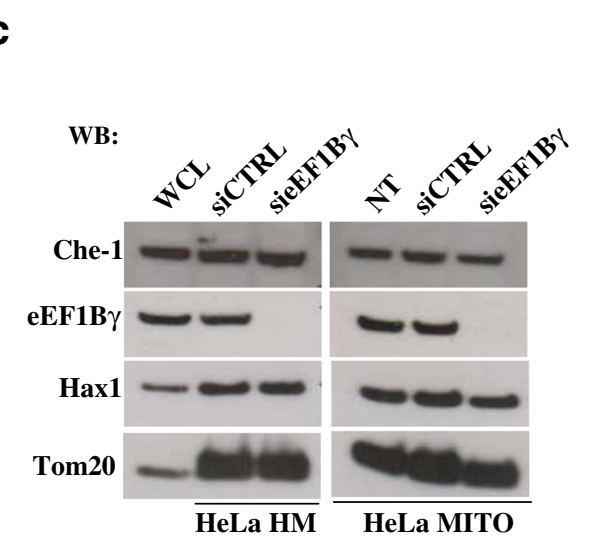

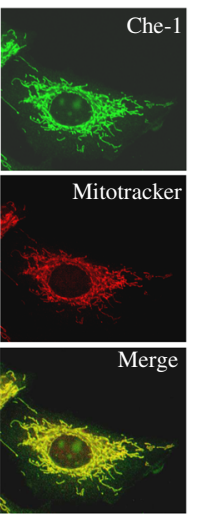

WB:

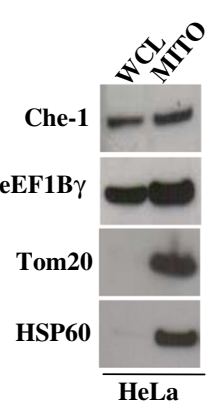

b
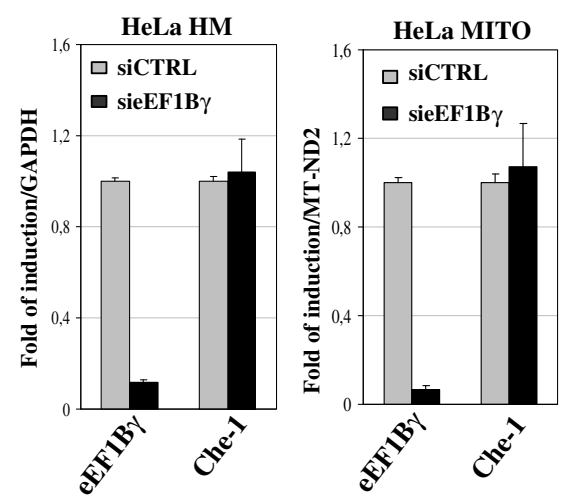

d
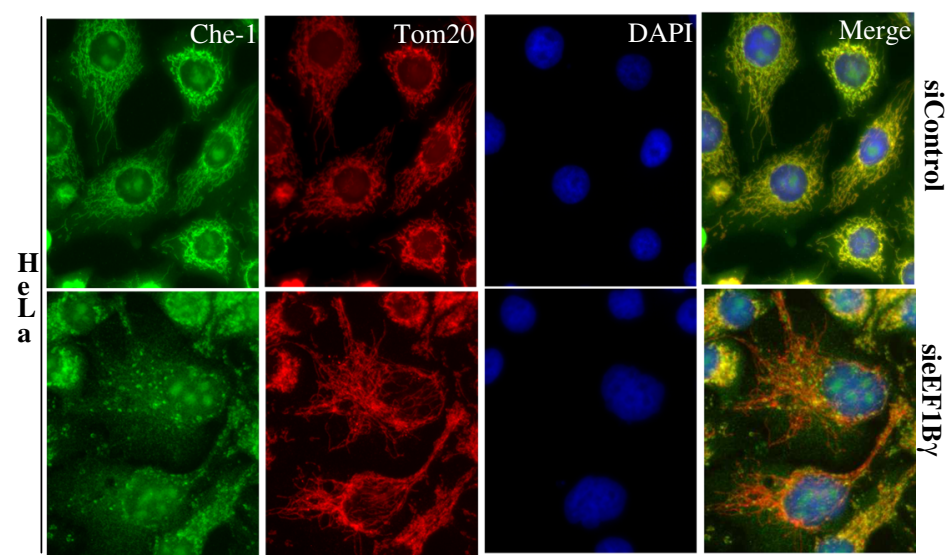

Fig. 4 Che-1 mitochondrial localization and impact of eEF1By depletion a Co-localization of endogenous Che-1, performed using the anti-Che-1 rat polyclonal antibody (green), and MitoTracker ${ }^{\oplus}$-Red, which stains mitochondria, in HeLa cells. Extensive co-localization (yellow) between Che-1 and MitoTracker ${ }^{\circledR}$-Red is visualized by the merged-color image. The panel represents high magnification images of the boxed area. Nuclei were labeled with Hoechst (blue). Scale bars: $10 \mu \mathrm{m}$ (left panel). On the right western blot analysis of HeLa whole-cell lysate and mitochondrial enriched fractions. The quality of the mitochondrial-enriched fraction was monitored using the anti-Tom20 rabbit polyclonal antibodies and the anti-HSP60 monoclonal antibodies. b Quantitative real time RT-PCR (qPCR) analysis of the eEF1BY (left) and Che-1 (right) mRNAs in heavy membrane or mitochondrial extracts from HeLa cells (siRNA-Control and siRNA-eEF1Bץ). The gene expression ratio of eEF1BY and Che-1, normalized as indicated, are shown as the mean \pm SD from three independent experiments performed in triplicate. c Che-1 protein levels were determined with a western blot assay in mitochondrial extracts from HeLa cells treated with scrambled siRNA-Control and eEF1By-depleted by specific siRNA. Hax1 and Tom20 were used as mitochondrial markers. d Representative fluorescence images of HeLa cells treated with either siRNAControl or siRNA-eEF1By. Dual-label indirect immunofluorescence was performed with the anti-Che-1 rat polyclonal antibody (green) and the anti-Tom20 rabbit polyclonal antibody (red). Nuclei were stained with DAPI (blue)

shown that it also binds the promoter region of the vimentin gene $[5,18]$. Here, to identify further functional pathways in which eEF1By is involved, we put our efforts in the isolation and characterization of additional mRNAs recognized by eEF1By protein, using the RIP assay technology. To this end, we focused on the mitochondriaenriched heavy membrane (HM) subcellular fraction with the idea of assessing eEF1By involvement in mitochondrial and cytoskeletal metabolisms. Among the isolated mRNAs, we mainly found genes involved in cytoskeleton transport/ organization, translation and mitochondrial metabolism. We confirmed the presence of vimentin and p53 transcripts, already reported [18, 22]. By serendipity, we found the mRNA of the pol-II binding protein Che-1/ AATF. The human Che-1 3'UTR is characterized by the presence of a conserved RNA stem-loop structure that could be the target of eEF1By protein. By use of different imaging techniques (MS2-GFP and FISH combined with immunofluorescence), we visualized the co-localization/ interaction of endogenous eEF1B $\gamma$ with endogenous Che1 or vimentin mRNAs in peculiar granules accumulated in the cytoplasm around the nucleus.

The polysomal profile analysis reveals that the eEF1By protein is mainly present in the ribosome free mRNPs- 


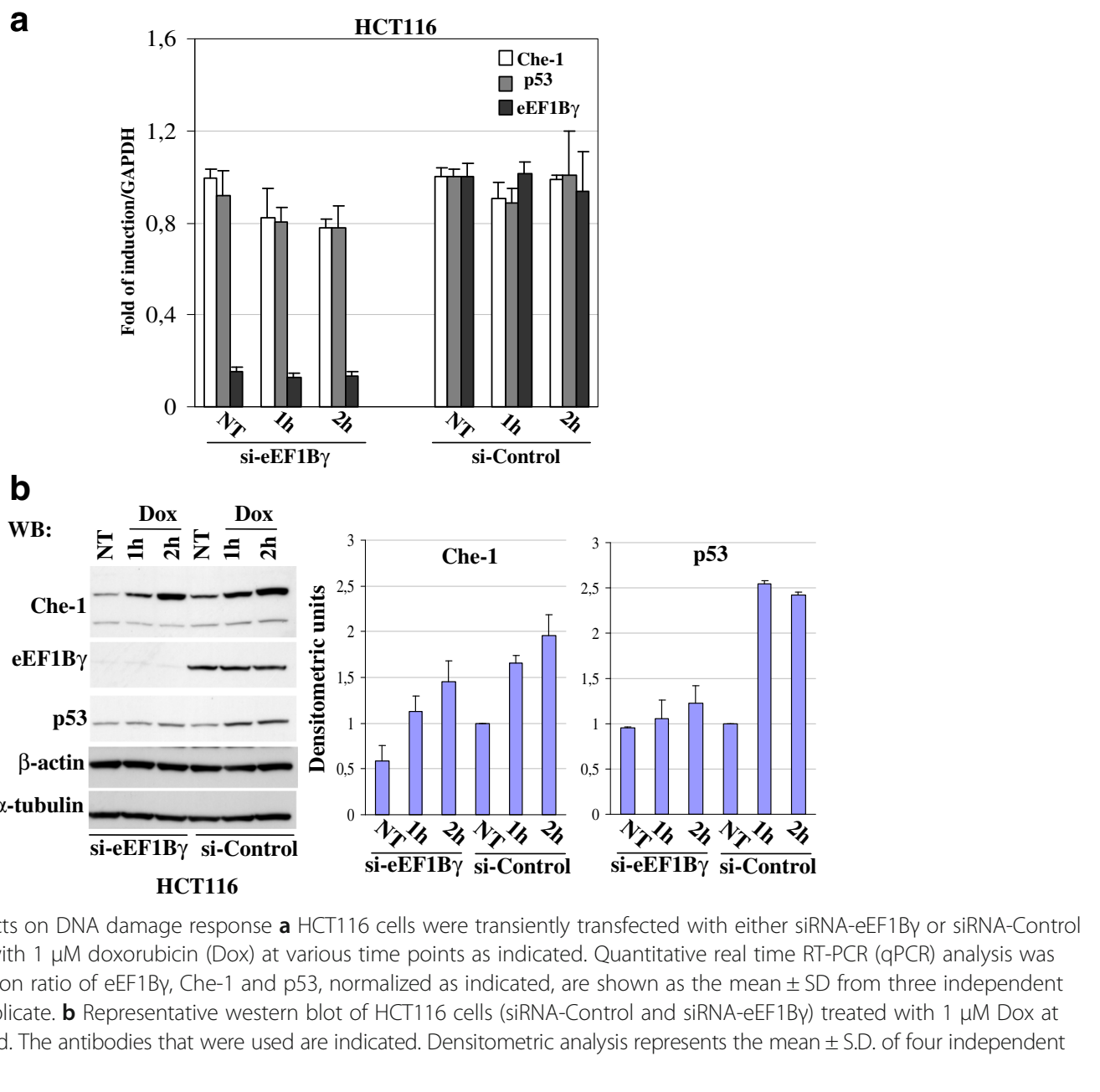

enriched fractions. These data together support the notion that the ability of eEF1By to bind selected mRNAs is fundamental to carrying out its non-canonical roles. A further eEF1By non-canonical role resides in its ability to recognize specific gene promoters. We have previously shown that eEF1By binds the promoter region of the vimentin gene, and here, we showed that eEF1By is also found in both Che-1 and TP53 promoters regions. These results suggest a role for eEF1By in nursing/trafficking selected mRNAs from the gene locus to the local product translation site.

These findings are consistent with the following notions: 1) eEF1By binds the p53 transcript and controls its stability, and we show here that eEF1By also binds Che-1 mRNA; 2) Fanciulli and colleagues demonstrated that Che-1 directly interacts with p53 and is involved in regulating p53 expression [37]; and 3) both Che-1 and eEF1By directly bind to the alpha-like pol II heterodimer. More precisely, eEF1By binds to the subunit POLR2C (RPB3), whereas Che-1 contacts the small subunit POLR2J (RPB11). These two subunits form a core subassembly unit of pol II and are considered the functional counterpart of the bacterial RNA polymerase alpha subunit homodimer. In bacteria, the alpha subunit homodimer associate with $\sigma$ factors that mediate promoter recognition [29-31].

With the aim of characterizing the eEF1By protein domain responsible for mRNA binding, we used a series of eEF1By deletion mutants in RIP assay. In our assays, only two deletion mutants retained minimal Che-1 and p53 mRNA binding ability, thus suggesting that eEF1By protein integrity is required for proper RNA binding activity.

Data reported in the literature have indicated a very wide Che-1 protein distribution, including the nucleolus, nucleus, cytoplasm, Golgi apparatus, centrosome and focal adhesion $[33,54,55]$. We have shown for the first time that Che-1 localizes at the mitochondria. Indeed, Che-1 has been reported to ameliorate mitochondrial dysfunction associated with the accumulation of superoxide [57]. Is it possible that eEF1By is important for transportation of the Che-1 mRNA to the mitochondria, and once the mRNA is there, eEF1By is dispensable for its translation. Garg's research group recently demonstrated that Che-1 
cooperates with miR-2909 in the regulation of mitochondrial uncoupling protein 2 (UCP2), a critical protein whose dysregulation is involved in the pathogenesis of a number of human diseases, including cancer $[58,59]$. The connection between eEF1By, Che-1 and p53 proteins and their transcripts indicated, for these genes, involvement in closely related pathways. Indeed, p53 is involved in regulation of the mitochondrial metabolism, playing multiple roles depending on its wild-type/mutation status and translocation into the mitochondria [60-62]. As wells as for Che-1, eEF1By could also participate to p53 localization and/or translation. In this scenario, eEF1B $\gamma$ affecting Che-1 and p53 RNA metabolism, could be an important player within functional networks interconnecting Che-1 and p53 proteins. The depletion of eEF1By induces mitochondrial fragmentation and disorganization; this phenomenon correlates with an aberrant Che-1 protein sub-cellular distribution, as we already described for vimentin intermediate filaments [5]. Because in a steady-state condition eEF1BY depletion produces almost no changes in Che-1 levels, we investigated the possible impact of eEF1By in stress pathways in which both Che-1 and p53 are involved such as DNA damage [33, 63, 64]. In a Dox-induced genotoxic stress in HCT116 cells, eEF1By depletion decreases p53 protein accumulation and slightly impacts also on Che-1 accumulation. Importantly, Che- 1 and p53 proteins are effectors of the DNA damage response machinery that is responsible for maintaining genome integrity and preventing tumorigenesis. Our data are in agreement with the role of eEF1By in cellular stress responses, suggesting that the DNA damage response pathway will be fundamental in further investigations of non-canonical eEF1By functions, pointing also at elucidating eEF1By role in tumorigenesis and cancer progression.

\section{Conclusions}

Using the RIP assay with eEF1By in the mitochondriaenriched HM fraction, we isolated several novel mRNAs involved in cytoskeleton transport/organization, translation and mitochondrial metabolism. Among the eEF1By complexed transcripts, we found the mRNA that encodes Che- 1 protein and we confirmed the presence of the p53 transcript. Importantly, we demonstrated that eEF1By binds to both Che- 1 and TP53 gene promoters. We described for the first time Che-1 mitochondrial localization. In a Dox-induced DNA damage assay, we show that eEF1B $\gamma$ depletion significantly decreases $\mathrm{p} 53$ protein accumulation and slightly impacts also on Che- 1 protein accumulation. Taking into account that eEF1By is able: 1) to bind directly pol II, 2) to bind to target gene promoters, 3 ) to bind their transcripts, 4) to accompany the mRNAs to the correct translation site and 5) to participate/enhance translation elongation through its detoxification GSTdomain and through its ability to anchor cytoskeleton, we suggest for eEF1By a role in cellular stress responses as primordial transcription/translation factor that links fundamental steps from transcription control to local translation.

\section{Additional files}

\begin{abstract}
Additional file 1: Table S1. Oligos used in the present study. (DOC $56 \mathrm{~kb}$ )
Additional file 2: Table S2. Different mRNAs associated to eEF1By. (DOC $42 \mathrm{~kb}$ )

Additional file 3: Figure S1. A. RIP assay output was analyzed by semiquantitative RT-PCR with specific primers to validate some of mRNAs coimmunoprecipitated with eEF1BY and they are listed in Table S2. B. The myc-eEF1By and MS2-GFP fusion proteins were expressed in HeLa cells with the report mRNA carrying both the MS2 binding site and the indicated 3' UTR. C. RIP assay-eEF1By mRNAs (Additional file 2: Table S2) analyzed by quantitative real time PCR (qPCR) in HeLa whole-cell lysates treated with siRNA as shown. The gene expression ratio between mRNAs and GAPDH are shown as the mean \pm SD from three independent experiments performed in triplicate. D. Representative western blot of HeLa whole-cell lysates treated or un-treated with siRNA as shown. The antibodies that were used are indicated. Densitometric analysis represents the mean \pm S.D. of 3 independent experiments (right panel). (PDF 208 kb)
\end{abstract}

Additional file 4: Figure S2. A. Chromatin immunoprecipitation was performed in $\mathrm{hSH}-\mathrm{SY} 5 \mathrm{Y}$ cells using anti-eEF1By rabbit polyclonal antibodies or no-Ab as a control. Immunoprecipitates from each sample were analyzed by PCR performed with primers specific for the human Che-1 promoter and for the human TP53 promoter. The thymidine kinase human promoter was amplified as a negative control. A sample representing linear amplification of the total input chromatin (input) was included in the PCR as a control. B. Co-localization of endogenous Che-1, performed with the anti-Che-1 rat polyclonal antibody (green), and the mitochondrial marker Tom20 (red), in hSH-SY5Y cells. Extensive co-localization (yellow) between Che-1 and Tom20 is visualized by the merged-color image. The boxed area represents a high magnification image of co-localization. Nuclei were labeled with DAPI (blue). Scale bars: $10 \mu \mathrm{m}$. C. Western blot analysis of hSH-SY5Y whole-cell lysate and mitochondrial enriched fraction. The quality of mitochondrial-enriched fractions was monitored using anti-HSP60 monoclonal antibodies and anti-Tom20 rabbit polyclonal antibodies. D. Quantitative real time PCR (qPCR) analysis of the eEF1BY and Che-1 mRNAs in hSH-SY5Y cells (siRNA-Control and siRNA-eEF1BY). The gene expression ratio between eEF1BY and GAPDH and between Che-1 and GAPDH are shown as the mean \pm SD from three independent experiments performed in triplicate. E. Representative Western blot of hSH-SY5Y wholecell lysates treated or un-treated with siRNA as shown. The antibodies that were used are indicated. (PDF $199 \mathrm{~kb}$ )

\section{Abbreviations}

Dox: Doxorubicin; eEF1BY: Eukaryotic Elongation Factor subunit 1B gamma; HM: Heavy membrane; MIT: Mitochondria; pol II: RNA polymerase II; POLR2C: RNA polymerase II (pol II) alpha-like subunit "C"; RIP assay: Ribonucleoprotein (RNP) immunoprecipitation assay

\section{Acknowledgments}

We thank Dr. R. G. Ruscitti for her precious constant assistance. We thank Dr F. Florenzano for valuable confocal microscopy assistance. This manuscript was edited for proper English language by Nature Publishing Group Language Editing; Certificate Verification Key: 0E6E-6013-7491-6303-B085.

\section{Funding}

This work was supported by Telethon-Italy (grant no. GGP14703), Associazione Italiana per la Ricerca sul Cancro (AIRC) Project grant no 15255 and FARMM-Onlus.

\section{Availability of data and materials}

All data generated and analysed during this study are included in this published article and its supplementary information files. 


\section{Authors' contributions}

Conceived and designed the experiments: CPi, NC, MGDC CPa. Performed the experiments: $\mathrm{CPi}, \mathrm{FG}, \mathrm{FDM}, \mathrm{AB}, \mathrm{MGDC}$, AO. Analyzed the data: $\mathrm{CPi}, \mathrm{NC}$ CPa, AO, MGDC, MF. Contributed reagents/materials/tools: MF, MAT. Wrote the paper: $\mathrm{CPi}, \mathrm{CPa}, \mathrm{NC}$. All authors read and approved the final manuscript.

\section{Competing interests}

The authors declared that they have no competing interests.

\section{Consent for publication}

Not applicable.

\section{Ethics approval and consent to participate}

Not applicable.

\section{Author details}

${ }^{1}$ CNR-Institute of Molecular Biology and Pathology, Department of Molecular Medicine, Sapienza University, Viale Regina Elena 291, 00161 Rome, Italy. ${ }^{2}$ CNR -Institute of Cell Biology and Neurobiology, Rome, Italy. ${ }^{3}$ IRCCS Fondazione Santa Lucia, Rome, Italy. ${ }^{4}$ Department of Research, Advanced Diagnostic, and Technological Innovation, SAFU Laboratory, Regina Elena Cancer Institute, Rome, Italy.

Received: 17 May 2016 Accepted: 10 September 2016 Published online: 17 September 2016

\section{References}

1. Merrick WC, Nyborg J. The protein biosynthesis elongation cycle. In Translational Control of Gene Expression. CSHL Press NY (Sonenberg N, Hershey J, Mathews M (Eds)). 2000; 89-125.

2. Le Sourd F, Boulben S, Le Bouffant R, Cormier P, Morales J, Belle R, MulnerLorillon O. eEF1B: At the dawn of the 21st century. Biochim Biophys Acta. 2006;1759(1-2):13-31.

3. Trosiuk TV, Shalak VF, Szczepanowski RH, Negrutskii BS, El'skaya AV. A noncatalytic $\mathrm{N}$-terminal domain negatively influences the nucleotide exchange activity of translation elongation factor 1Ba. FEBS J. 2016;283(3):484-97.

4. Esposito AM, Kinzy TG. The eukaryotic translation elongation Factor 1Bgamma has a non-guanine nucleotide exchange factor role in protein metabolism. J Biol Chem. 2010;285(49):37995-8004.

5. Corbi N, Batassa EM, Pisani C, Onori A, Di Certo MG, Strimpakos G, Fanciulli M, Mattei E, Passananti C. The eEF1Y subunit contacts RNA polymerase II and binds vimentin promoter region. PLoS One. 2010;5(12):e14481.

6. Sasikumar AN, Perez WB, Kinzy TG. The many roles of the eukaryotic elongation factor 1 complex. Wiley Interdiscip Rev RNA. 2012;3(4):543-55.

7. Veremieva M, Kapustian L, Khoruzhenko A, Zakharychev V, Negrutskii B, El'skaya A. Independent overexpression of the subunits of translation elongation factor complex eEF1H in human lung cancer. BMC Cancer. 2014;14:913.

8. Al-Maghrebi M, Anim JT, Olalu AA. Up-regulation of eukaryotic elongation factor-1 subunits in breast carcinoma. Anticancer Res. 2005;25(3c):2573-7.

9. Chi K, Jones DV, Frazier ML. Expression of an elongation factor 1 gammarelated sequence in adenocarcinomas of the colon. Gastroenterology. 1992;103(1):98-102.

10. Mimori K, Mori M, Tanaka S, Akiyoshi T, Sugimachi K. The overexpression of elongation factor 1 gamma mRNA in gastric carcinoma. Cancer. 1995;75(6 Suppl):1446-9.

11. Lew Y, Jones DV, Mars WM, Evans D, Byrd D, Frazier ML. Expression of elongation factor-1 gamma-related sequence in human pancreatic cancer. Pancreas. 1992; 7(2):144-52.

12. Ruggero D. Translational control in cancer etiology. Cold Spring Harb Perspect Biol. 2013;5(2).

13. Chen B, Tan Z, Gao J, Wu W, Liu L, Jin W, Cao Y, Zhao S, Zhang W, Qiu Z, Liu D, Mo X, Li W. Hyperphosphorylation of ribosomal protein $S 6$ predicts unfavorable clinical survival in non-small cell lung cancer. J Exp Clin Cancer Res. 2015;34:126

14. Yoshida GJ. Metabolic reprogramming: the emerging concept and associated therapeutic strategies. J Exp Clin Cancer Res. 2015;34:111.

15. Udensi UK, Tchounwou PB. Dual effect of oxidative stress on leukemia cancer induction and treatment. J Exp Clin Cancer Res. 2014;33:106.
16. Mimori K, Mori M, Inoue H, Ueo H, Mafune K, Akiyoshi T, Sugimachi K. Elongation factor 1 gamma mRNA expression in oesophageal carcinoma. Gut. 1996;38(1):66-70.

17. Kim S, Kellner J, Lee $\mathrm{CH}$, Coulombe PA. Interaction between the keratin cytoskeleton and eEF1Bgamma affects protein synthesis in epithelial cells. Nat Struct Mol Biol. 2007:14(10):982-3.

18. Al-Maghrebi M, Brulé H, Padkina M, Allen C, Holmes WM, Zehner ZE. The 3' untranslated region of human vimentin mRNA interacts with protein complexes containing eEF-1gamma and HAX-1. Nucleic Acids Res. 2002;30(23):5017-28

19. Shi Y, Di Giammartino DC, Taylor D, Sarkeshik A, Rice WJ, Yates 3rd JR, Frank J, Manley JL. Molecular architecture of the human pre-mRNA 3' processing complex. Mol Cell. 2009:33(3):365-76.

20. Tang HL, Lung HL, Wu KC, Le AH, Tang HM, Fung MC. Vimentin supports mitochondrial morphology and organization. Biochem J. 2008;410(1):141-6.

21. Chernoivanenko IS, Matveeva EA, Gelfand VI, Goldman RD, Minin AA. Mitochondrial membrane potential is regulated by vimentin intermediate filaments. FASEB J. 2015:29(3):820-7.

22. Jo JH, Chung TM, Youn H, Yoo JY. Cytoplasmic parafibromin/hCdc73 targets and destabilizes p53 mRNA to control p53-mediated apoptosis. Nat Commun. 2014,5:5433.

23. Liu D, Sheng C, Gao S, Jiang W, Li J, Yao C, Chen H, Wu J, Chen S, Huang W eEF1BY is a positive regulator of NF-kB signaling pathway. Biochem Biophys Res Commun. 2014;446(2):523-8

24. Matassa DS, Amoroso MR, Agliarulo I, Maddalena F, Sisinni L, Paladino S, Romano S, Romano MF, Sagar V, Loreni F, Landriscina M, Esposito F. Translational control in the stress adaptive response of cancer cells: a novel role for the heat shock protein TRAP1. Cell Death Dis. 2013;4:e851.

25. Sainsbury S, Bernecky C, Cramer P. Structural basis of transcription initiation by RNA polymerase II. Nat Rev Mol Cell Biol. 2015;16(3):129-43.

26. Kornberg RD. Mediator and the mechanism of transcriptional activation. Trends Biochem Sci. 2005;30(5):235-9.

27. Fanciulli M, Bruno T, Di Padova M, De Angelis R, Lovari S, Floridi A, Passananti C. The interacting RNA polymerase II subunits, hRPB11 and hRPB3, are coordinately expressed in adult human tissues and downregulated by doxorubicin. FEBS Lett. 1998;427(2):236-40.

28. Davis JA, Takagi Y, Kornberg RD, Asturias FA. Structure of the yeast RNA polymerase II holoenzyme: Mediator conformation and polymerase interaction. Mol Cell. 2002;10(2):409-15.

29. Woychik NA, McKune K, Lane WS, Young RA. Yeast RNA polymerase II subunit RPB11 is related to a subunit shared by RNA polymerase I and III. Gene Expr. 1993;3(1):77-82

30. Corbi N, Di Padova M, De Angelis R, Bruno T, Libri V, lezzi S, Floridi A, Fanciulli M, Passananti C. The alpha-like RNA polymerase II core subunit 3 (RPB3) is involved in tissue-specific transcription and muscle differentiation via interaction with the myogenic factor myogenin. FASEB J. 2002:16(12):1639-41.

31. Harden TT, Wells CD, Friedman LJ, Landick R, Hochschild A, Kondev J, Gelles J. Bacterial RNA polymerase can retain $\sigma 70$ throughout transcription. Proc Natl Acad Sci U S A. 2016;113(3):602-7.

32. Passananti $C$, Fanciulli $M$. The anti-apoptotic factor Che-1/AATF links transcriptional regulation, cell cycle control, and DNA damage response. Cell Div. 2007:2:21

33. lezzi S, Fanciulli M. Discovering Che-1/AATF: a new attractive target for cancer therapy. Front Genet. 2015:6:141.

34. Bruno T, lezzi S, Fanciulli M. Che-1/AATF: A Critical Cofactor for Both WildType- and Mutant-p53 Proteins. Front Oncol. 2016:6:34

35. Vousden KH, Lane DP. p53 in health and disease. Nat Rev Mol Cell Biol. 2007:8(4):275-83.

36. Muller PA, Vousden KH. p53 mutations in cancer. Nat Cell Biol. 2013;15(1):2-8.

37. Desantis A, Bruno T, Catena V, De Nicola F, Goeman F, lezzi S, Sorino C, Gentileschi MP, Germoni S, Monteleone V, Pellegrino M, Kann M, De Meo PD, Pallocca M, Höpker K, Moretti F, Mattei E, Reinhardt HC, Floridi A, Passananti C, Benzing T, Blandino G, Fanciulli M. Che-1 modulates the decision between cell cycle arrest and apoptosis by its binding to p53. Cell Death Dis. 2015:6:e1764.

38. Bruno T, Desantis A, Bossi G, Di Agostino S, Sorino C, De Nicola F, lezzi S, Franchitto A, Benassi B, Galanti S, La Rosa F, Floridi A, Bellacosa A, Passanant C, Blandino G, Fanciulli M. Che-1 promotes tumor cell survival by sustaining mutant p53 transcription and inhibiting DNA damage response activation. Cancer Cell. 2010;18(2):122-34. 
39. Karbowski M, Neutzner A, Youle RJ. The mitochondrial E3 ubiquitin ligase MARCH5 is required for Drp1 dependent mitochondrial division. J Cell Biol. 2007;178(1):71-84

40. Keene JD, Komisarow JM, Friedersdorf MB. RIP-Chip: the isolation and identification of mRNAs, microRNAs and protein components of ribonucleoprotein complexes from cell extracts. Nat Protoc. 2006;1(1):302-7.

41. Onori A, Pisani C, Strimpakos G, Monaco L, Mattei E, Passananti C, Corbi N. Utroup is a novel six zinc finger artificial transcription factor that recognises 18 base pairs of the utrophin promoter and efficiently drives utrophin upregulation. BMC Mol Biol. 2013;14:3.

42. Gabanella F, Pisani C, Borreca A, Farioli-Vecchioli S, Ciotti MT, Ingegnere T, Onori A, Ammassari-Teule M, Corbi N, Canu N, Monaco L, Passananti C, Di Certo MG. SMN affects membrane remodelling and anchoring of the protein synthesis machinery. J Cell Sci. 2016;129(4):804-16.

43. Raj A, Tyagi S. Detection of individual endogenous RNA transcripts in situ using multiple singly labeled probes. Methods Enzymol. 2010;472:365-86.

44. Grünwald D, Singer RH, Czaplinski K. Cell biology of mRNA decay. Methods Enzymol. 2008:448:553-77.

45. Li Q, Lau A, Morris TJ, Guo L, Fordyce CB, Stanley EF. A syntaxin 1, Galpha(o), and $\mathrm{N}$-type calcium channel complex at a presynaptic nerve terminal: analysis by quantitative immunocolocalization. J Neurosci. 2004;24(16):4070-81.

46. Fanciulli M, Bruno T, Di Padova M, De Angelis R, lezzi S, lacobini C, Floridi A, Passananti C. Identification of a novel partner of RNA polymerase II subunit 11, Che-1, which interacts with and affects the growth suppression function of Rb. FASEB J. 2000;14(7):904-12

47. Zehner ZE, Shepherd RK, Gabryszuk J, Fu TF, Al-Ali M, Holmes WM. RNAprotein interactions within the 3 'untranslated region of vimentin mRNA Nucleic Acids Res. 1997;25(16):3362-70.

48. Bermano G, Shepherd RK, Zehner ZE, Hesketh JE. Perinuclear mRNA localisation by vimentin 3'-untranslated region requires a 100 nucleotide sequence and intermediate filaments. FEBS Lett. 2001:497(2-3):77-81.

49. Sasvari Z, Izotova L, Kinzy TG, Nagy PD. Synergistic roles of eukaryotic translation elongation factors $1 \mathrm{~B} y$ and $1 \mathrm{~A}$ in stimulation of tombusvirus minus-strand synthesis. PLoS Pathog. 2011;7(12):e1002438.

50. Gruber AR, Lorenz R, Bernhart SH, Neuböck R, Hofacker IL. The Vienna RNA websuite. Nucleic Acids Res. 2008;36(Web Server issue):W70-4.

51. Querido $E_{t}$ Chartrand P. Using fluorescent proteins to study mRNA trafficking in living cells. Methods Cell Biol. 2008;85:273-92.

52. Sanchez G, Dury AY, Murray LM, Biondi O, Tadesse H, El Fatimy R, Kothary R, Charbonnier F, Khandjian EW, Côté J. A novel function for the survival motoneuron protein as a translational regulator. Hum Mol Genet. 2013;22(4):668-84.

53. Dahl JA, Collas P. A rapid micro chromatin immunoprecipitation assay (microChIP). Nat Protoc. 2008;3(6):1032-45

54. Sorino C, Bruno T, Desantis A, Di Certo MG, lezzi S, De Nicola F, Catena V, Floridi A, Chessa L, Passananti C, Cundari E, Fanciulli M. Centrosomal Che-1 protein is involved in the regulation of mitosis and DNA damage response by mediating pericentrin (PCNT)-dependent Chk1 protein localization. J Biol Chem. 2013;288(32):23348-57.

55. Ishigaki S, Fonseca SG, Oslowski CM, Jurczyk A, Shearstone JR, Zhu LJ, Permutt MA, Greiner DL, Bortell R, Urano F. AATF mediates an antiapoptotic effect of the unfolded protein response through transcriptional regulation of AKT1. Cell Death Differ. 2010;17(5):774-86.

56. Williams AB, Schumacher B. p53 in the DNA-Damage-Repair Process. Cold Spring Harb Perspect Med. 2016;6(5).

57. Xie J, Guo Q. Apoptosis antagonizing transcription factor protects renal tubule cells against oxidative damage and apoptosis induced by ischemia-reperfusion. J Am Soc Nephrol. 2006;17(12):3336-46.

58. Robbins D, Zhao Y. New aspects of mitochondrial Uncoupling Proteins (UCPS) and their roles in tumorigenesis. Int J Mol Sci. 2011;12(8):5285-93.

59. Kaul D, Sharma S, Garg A. Mitochondrial uncoupling protein (UCP2) gene expression is regulated by miR-2909. Blood Cells Mol Dis. 2015;55(1):89-93.

60. Kamp WM, Wang PY, Hwang PM. TP53 mutation, mitochondria and cancer. Curr Opin Genet Dev. 2016:38:16-22.

61. Park JH, Zhuang J, Li J, Hwang PM. p53 as guardian of the mitochondrial genome. FEBS Lett. 2016;590(7):924-34.

62. Qin LS, Jia PF, Zhang ZQ, Zhang SM. ROS-p53-cyclophilin-D signaling mediates salinomycin-induced glioma cell necrosis. J Exp Clin Cancer Res. 2015;34:57
63. Dutertre M, Lambert S, Carreira A, Amor-Guéret M, Vagner S. DNA damage: RNA-binding proteins protect from near and far. Trends Biochem Sci. 2014;39(3):141-9.

64. Truitt ML, Ruggero D. New frontiers in translational control of the cancer genome. Nat Rev Cancer. 2016;16(5):288-304.

65. The ViennaRNA Web Services. http://rna.tbi.univie.ac.at. Accessed 12 May 2016.

\section{Submit your next manuscript to BioMed Central and we will help you at every step:}

- We accept pre-submission inquiries

- Our selector tool helps you to find the most relevant journal

- We provide round the clock customer support

- Convenient online submission

- Thorough peer review

- Inclusion in PubMed and all major indexing services

- Maximum visibility for your research

Submit your manuscript at www.biomedcentral.com/submit

) Biomed Central 